\title{
Further Education as an Integrative Pivot of Lifelong Learning
}

\author{
Liya D. Torosyan ${ }^{1} \mathrm{PhD}$ of Pedagogic Sciences; \\ Katerina A. Stepanenko ${ }^{2} \mathrm{PhD}$ of Philological Sciences; \\ Vera V. Semina ${ }^{3} \mathrm{PhD}$ of Pedagogic Sciences; Armine E. Grigoryan ${ }^{4}$ \\ Plekhanov Russian University of Economics, Russia \\ liya-torosyan@yandex.ru'; valentinova_kate@mail.ru²; semina_v_v@mail.ru33; grigarm7@yandex.ru²
}

\begin{abstract}
: this study is focused on analysing further education as an integrative pivot of lifelong learning. Modern universities are currently undergoing changes in terms of transformation into entrepreneurial units aimed at commercialization of educational services including further educational programs. The topicality of the research is stipulated by the global urge to stay competitive in the saturated educational services market due to the increasing number of institutions both state and private rendering educational services. The aim of the study is to reveal the needs for further education of representatives among young and academic audiences and devise a course syllabus within further educational programs relevant to the detected requirements of potential listeners. The authors put forward a hypothesis suggesting that there are courses whose unique selling points might be attractive to learners. The results obtained through the questionnaires demonstrated that students and academic staff envision an ideal course to meet all their educational needs in a different way which gives momentum to reconsider the format of rendering educational services and recompose further educational programs making them client-friendly in terms of duration, group size, location, range of courses available and flexibility regarding program contents. The results of the study are of significance due to the fact that further educational programs will be far more susceptible to the needs and requirements of the target audience possessing such features as adjustability, flexibility and modularity.
\end{abstract}

Keywords: further education, lifelong learning, academic community, educational services.

\section{Introduction}

Reflecting present-day realities many universities are being transformed into business units aiming at the commercialization of educational services including further education programs within the concept of Lifelong Learning. The concept emerged in 1960s and was in the focus of numerous researchers (Billett, 2018; Cendon, 2018; Formenti, West, 2018; Knapper, Cropley, 2000; Lengrand, 2016; Oliver, 2019; Tight, 2003; Wain, 2016). The central idea behind all these studies was the same: provision of education and training opportunities for every person throughout their lives. M. Tight argues for a rejection of a model of education that is confined to childhood, adolescence and early adulthood (Tight, 2003, 39). Thus, learning is not age-related and a person has got an opportunity to study and acquire the necessary skills to ensure job security and career progress having been aware of the gap between what he knows and what he doesn't know as the motivation to learn through his life (Jarvis, 2007). It's unfeasible to gain all knowledge, skills and competences while studying at school or university, a person needs to continually expand his knowledge, fine-tune his skills and competences through life span development (Sharples, 2000). The International Handbook of Lifelong Learning, edited by D. Aspin, J. Chapman, M. Hatton and Y. Sawano (2001) states that the era of technologies and changeable world gives momentum to people who strive for staying afloat in terms of employability and hence get involved in further education.

It's worth mentioning that the educational services market in Moscow is developing at a steady pace due to the following factors:

$\checkmark$ the concept of Lifelong Learning, which is implemented in continuous education in the form of courses, trainings and workshops.

$\checkmark$ practice-oriented education, which is stipulated by changes in the requirements of employers for the competencies of graduates, who should possess a set of soft skills along with hard ones;

$\checkmark$ the willingness of both parents and students themselves to invest in their further education in terms of learning foreign languages, which will serve as the key to a successful career and will pay off in the short run. 
The market for further education services is represented by a wide variety of educational institutions that either fully specialize in providing commercial educational services or this activity is carried out in addition to the core activities, and Plekhanov Russian University of Economics is not an exception.

Further education focuses on meeting educational and professional needs, expanding and updating knowledge and skills in the selected field with no change in the level of education. Further education was reflected in a number of studies (Li, 2014; Alexandrova, Glukhov, 2021; Kireyev, Zhabotynska, 2020; Kovalenko, Kovalenko, 2019; Vaganova et al., 2019).

Further education can be implemented in different forms, both short-term and long-term. Short-term programs are traditionally designed for 16-72 academic hours with a subsequent acquisition of a completion certificate. Long-term programs are normally designed for a long period of study with a subsequent acquisition of a professional retraining diploma in the selected field. Long-term programs are devised for 250-500 academic hours and more. At the end of a long-term program students receive a professional retraining diploma, entitling them to conduct professional activities in the subject area or a diploma with a certain qualification.

According to the Federal State Statistics Service of the Russian Federation in 2018, the number of institutions of further education in Russia exceeded 19000, the majority of which were commercial organizations $(85.1 \%)$. Further education services are provided by both organizations specializing in a narrow field, for example, management, marketing and multidisciplinary educational organizations, for example, centres of further education as independent or integrated structures at universities. Further education is becoming increasingly important for those categories who do not work in the specialty they have been trained in, do not have sufficient work experience, but plan future career growth, striving for an extended set of competencies to solve the assigned professional tasks. Regarding foreign language learning the following reasons for further education can be listed.

It should be noted that the command of a foreign language significantly improves the chance of moving up the career ladder and getting a pay rise within the context of market globalization, the integration of foreign companies into the Russian business and the expansion of business contacts of Russian companies abroad.

The mentality of people is being transformed under the influence of the national currency volatility, which leads to people's willingness to invest in further education. This transformation has a scientific basis as education is considered to be the key element of human capital. In the monograph "Social Policy in Human Capital Management" P. Lemanova (2013) states that in 192 countries with transition economies economic growth is stipulated by physical capital, natural capital, human and social capital in the following percentage $16 \%, 20 \%$ and $64 \%$ respectively.

S. Dyatlov (2004) claims that human capital is a certain stock of health, knowledge, skills, abilities, motivation accumulated and hence implemented by a person to contribute to the growth of labour productivity and thereby to affect the increase in the income of a given person.

Investments in education are becoming increasingly attractive with the introduction of distance technologies enabling to build your own learning path in a comfortable mode and on the job. Here are the statistics on the number of students in further education programs in Russia in 2014-2018 according to BusinesStat (Table 1).

Table 1

The number of students in further education programs in the Russian Federation in 2014-2018

\begin{tabular}{|c|c|c|c|c|c|}
\hline Year & $\mathbf{2 0 1 4}$ & $\mathbf{2 0 1 5}$ & $\mathbf{2 0 1 6}$ & $\mathbf{2 0 1 7}$ & $\mathbf{2 0 1 8}$ \\
\hline Number of students, million people & 4.37 & 4.30 & 5.29 & 5.33 & 5.52 \\
\hline \% to the previous year & - & -1.6 & 23.0 & 0.9 & 3.4 \\
\hline
\end{tabular}

BusinesStat forsaw the number of students enrolled in further education programs from 2019 to 2023. The data are given in Table 2. 
Table 2

The number of students in further education programs in the Russian Federation in 2019-2023

\begin{tabular}{|c|c|c|c|c|c|}
\hline \multicolumn{1}{|c|}{ Year } & $\mathbf{2 0 1 9}$ & $\mathbf{2 0 2 0}$ & $\mathbf{2 0 2 1}$ & $\mathbf{2 0 2 2}$ & $\mathbf{2 0 2 3}$ \\
\hline Number of students, million people & 5.62 & 5.71 & 5.79 & 5.87 & 5.92 \\
\hline \% on the previous year & 1.8 & 1.7 & 1.4 & 1,3 & 0.9 \\
\hline
\end{tabular}

As it is seen from the table, the number of students involved in further education is steadily rising. This forecast might turn to be less optimistic in reality, given the worsening epidemiological situation in the Russian Federation and a decrease in real income of the population.

Furthermore, modern universities tend towards commercialization of education, which means that they have to make educational programs available on the market. This very fact highlights an irrefutable issue on further educational programs re-composition that will meet and even exceed the divergent needs of academic community and university youth expanding the prospects for being involved in the act of learning throughout life.

The aim of the study is to analyse the demand for further educational services in terms of foreign languages and to specify the marketable features of the further educational programs offered to the public.

\section{Methodology}

To fulfil the stated aim the following tasks were defined: to perform a theoretical analysis to back up practical findings; to interpret of the results obtained through the poll, and to determine the further educational programs' parameters appealing to the potential listeners among young and academic audiences.

The authors of the research paper put forward a hypothesis suggesting that there are foreign language courses with pre-set parameters targeted at certain clients which are able to successfully compete in the market of further educational services and provide a stable increase in learners' number.

The authors formulated research questions which provide an insight into the analysis of supply and demand on the market of further educational services in terms of specialized courses of foreign languages, format of educational services rendered in terms of duration, choice among 'brick-andmortar', 'click-and-mortar' or online, group size, range of courses (general, business, field-specific), flexibility regarding program contents. The research questions were framed as follows:

1) What are the needs of young learners in terms of further education?

2) What are the needs of representatives of the academic community in terms of further education?

To collect precise data on the abovementioned research questions the authors worded sub questions clarifying the enquiry:

3) Which format (face-to-face, online, mixed) of classes is the most preferable?

4) Which course duration (3-24 months) is considered to be the most effective for language learning?

5) What is the number of students in the group (8-14 students) most comfortable to interact?

6) Would you choose the possibility to select modules of the course (yes, no)?

7) What are the preferences in choosing the language course (field-specific or general)?

8) What are the preferences in choosing courses location (in-house or outside)?

It should be noted that both groups of participants were asked the same sub questions.

Participants. The research involved two groups of participants. The first group was represented by university youth (363 students in total from three different institutions of higher education: Plekhanov Russian University of Economics, RUDN University, The Russian Presidential Academy of National Economy and Public Administration, Mdn age -21). The second group was represented by the academic community (45 participants particularly heads of different structural divisions of Plekhanov Russian University of Economics, Mdn age - 38).

The participants were thoroughly informed about the purpose of the research and voluntarily took part in it. 
Methods. To achieve the aim of the study, the researchers' team used a fusion of methods such as Qualitative and Quantitative data analysis:

1) Qualitative data analysis includes: online interviews with open-ended questions to collect opinions of respondents represented by students' and academic community; participant observation.

2) Quantitative data analysis includes: online poll with restricted questions via ENQ (Educational Needs Questionnaire) to identify educational preferences of potential listeners.

ENQ is designed to investigate the learning needs and preferences of the target audience and bridge the gap between what exists and what is expected. ENQ enables to conduct a needs analysis which is meant to specify the parameters of a course including course syllabus, the selection and sequencing of course content, course duration and intensity (Nunan, 2013; Sönmez, 2019).

Procedure. The research incorporates two stages: the first stage focuses on the student audience, the second stage embraces the academic community, specifically teaching staff and employees. The authors conducted needs analysis the goal of which was "to determine the current and the desired performance" (Biech, 2005, 51).

\section{Results and Discussion}

As mentioned previously, the authors formulated the research questions and made an attempt to shed light on each of them during the study. The first research question implicates student-based studies aimed at identification of educational needs among a young audience.

According to the first research subquestion, the authors set themselves the task to find out which format of training is preferable for learners. The respondents had to weigh in on face-to-face, mixed, and purely online formats. The results are represented below.

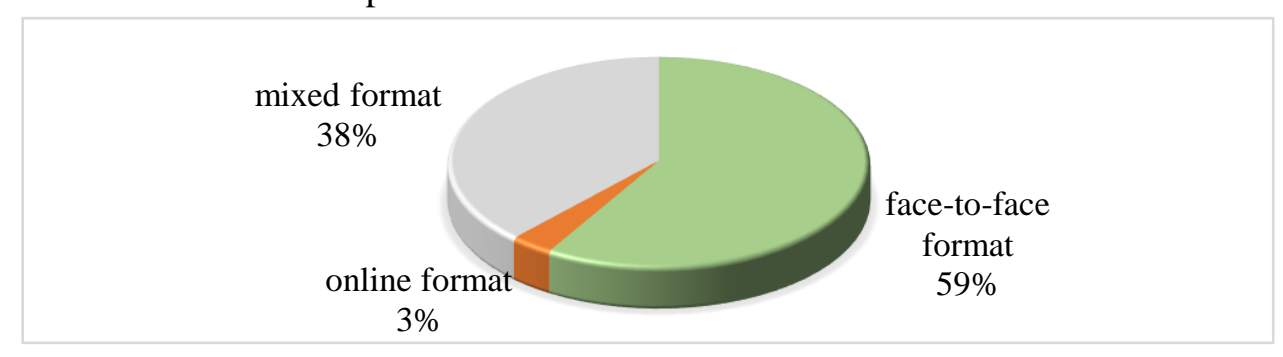

Figure 1. The format of training for continuing education programs.

The presented figure (Figure 1) demonstrates the proportion of learners distributed by format. 213 respondents supported the face-to-face format, 138 respondents would prefer a mixed learning format and only 12 respondents chose the online format.

According to the second research subquestion, the respondents were asked to provide their opinion regarding the duration of courses ranging between 3 and 24 months (Figure 2).

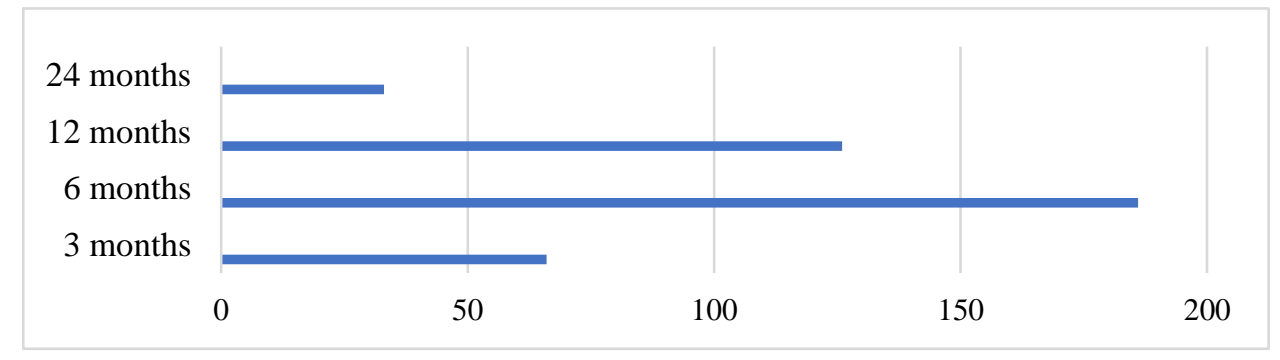

Figure 2. Course duration.

The most attractive was the course lasting 6 months (186 people), this was followed by the 12 months option (126 people), 3 months and 24 months courses were selected by 66 and 33 respondents respectively. It should be noted that the calculation took into account the answers where the respondent demonstrated hesitance and gave two options (the most frequent - 3/6 months, 6/12 months). Three respondents preferred not to answer. 
According to the third research sub question, the authors aimed at identifying the preferable group size in terms of the number of learners (Figure 3).

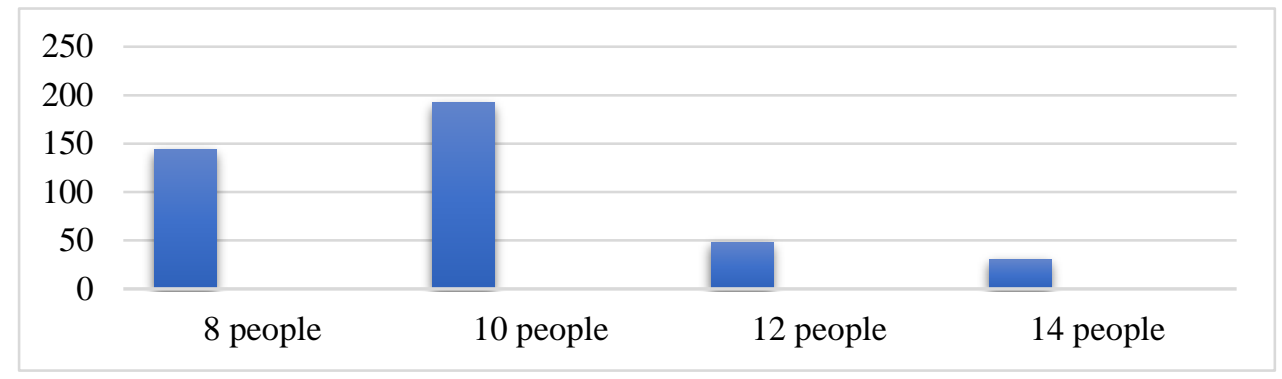

Figure 3. The number of students in the group.

The absolute leader was the answer "10 people" (192 votes), 144 votes came to the option " 8 people", the least interesting options seemed to be "12 people" (48 votes) and "14 people" (30 votes) correspondingly. It should be mentioned that dual answers (" $8 / 10$ people in the group" - 42 respondents, "10/12 people in the group" -18 respondents) were taken into consideration as well. 9 respondents held back and gave no answer.

Reflecting upon the fourth research sub question regarding opportunities for module selection within the course (Figure 4) the overwhelming majority of participants responded positively (327 votes), whereas only 7 participants reacted negatively. 29 respondents could not provide any feedback.

According to the fifth research sub-question, when choosing between language courses "General" and "Field specific" (Figure 5) the majority of the respondents gave preference to the field-specific course which accounted for approximately $58 \%$ (210 votes). 152 respondents showed an interest in the "General" option (roughly $42 \%$ ). The remaining 1 respondent showed no enthusiasm towards the provided options.

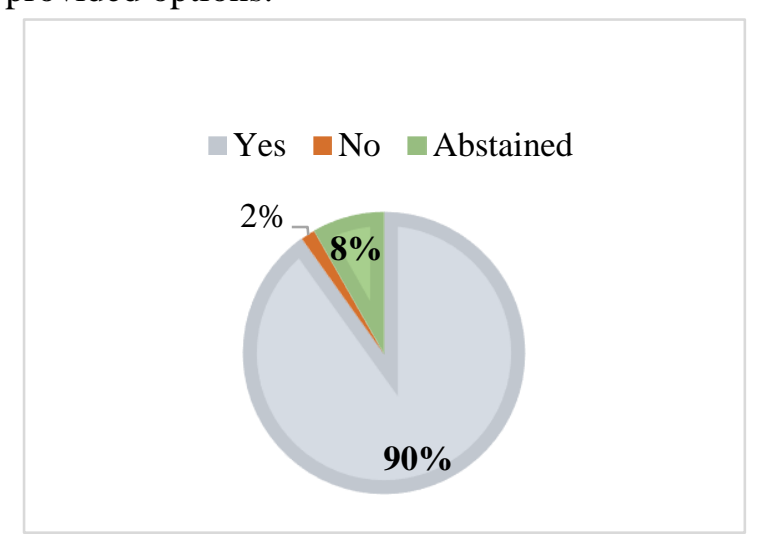

Figure 4. Ability to select modules in the course.

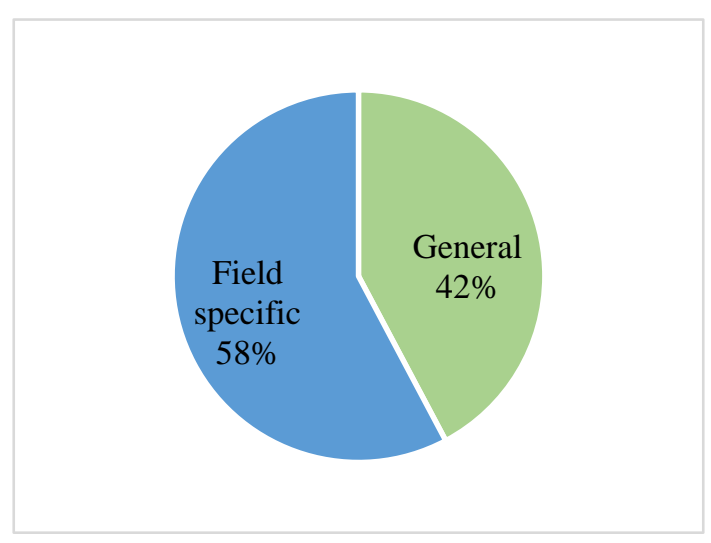

Figure 5. Preference when choosing a language course.

It should be noted that Business English course did not generate interest from the student audience. The experience of teaching English at a university shows that in most cases students master business terminology during the period of study, however, to build a reasoned and coherent written and spoken language, they lack a general spoken thesaurus.

As regards the sixth research sub question (Figure 6), most of the respondents went for the option "At the university (in-house)" - 326 votes, 36 votes came to the option "Outside the university" and only one person gave no answer. 


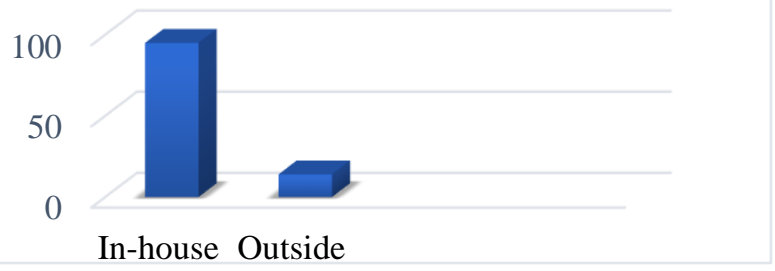

Figure 6. Preferences for courses location.

At the second stage, a survey was conducted among the heads of structural divisions of PRUE. The second research question implies staff-based studies focused on revealing educational needs. Reflecting upon the format of further education programs for teaching staff and employees (Figure 7) the respondents prioritized the given options in the following order: face-to-face format (73\%- 33 votes), mixed format (20\%- 9 votes), online format ( $7 \%-3$ votes).

\section{$\square$ face-to-face format $\square$ mixed format $\square$ online format}

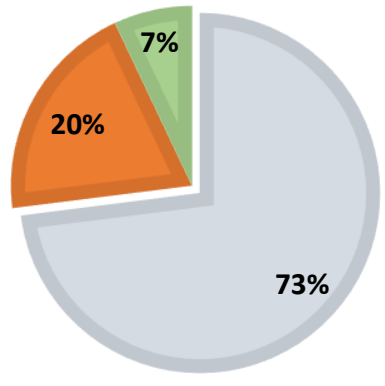

Figure 7. The format of training employees for further professional education programs.

Regarding the course duration for employees (Figure 8) the largest number of respondents (30 votes) opted for a course up to 3 months, while the rest of the votes ( 15 respondents) were distributed relatively evenly among the remaining options (6 months, 12 months, 24 months). As to the selection of modules within the course (Figure 9) the overwhelming majority of respondents (44 votes) consider it necessary to provide learners with such an opportunity. Only one respondent answered negatively.

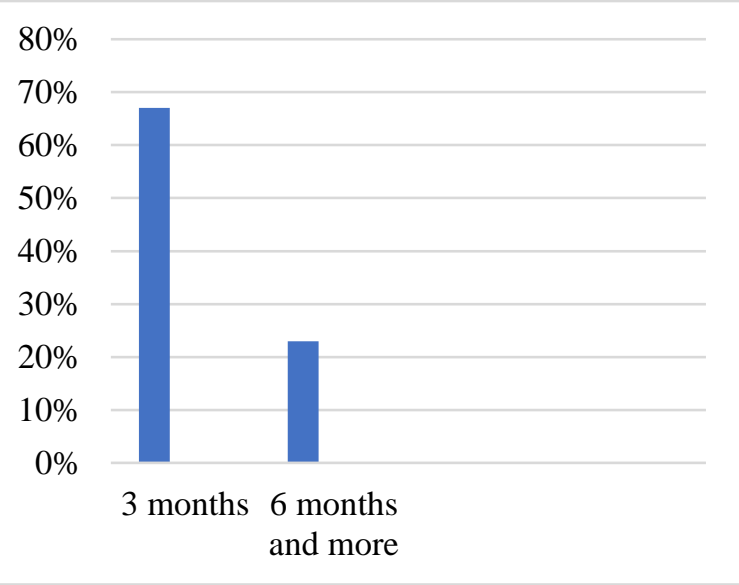

Figure 8. Course duration for employees.

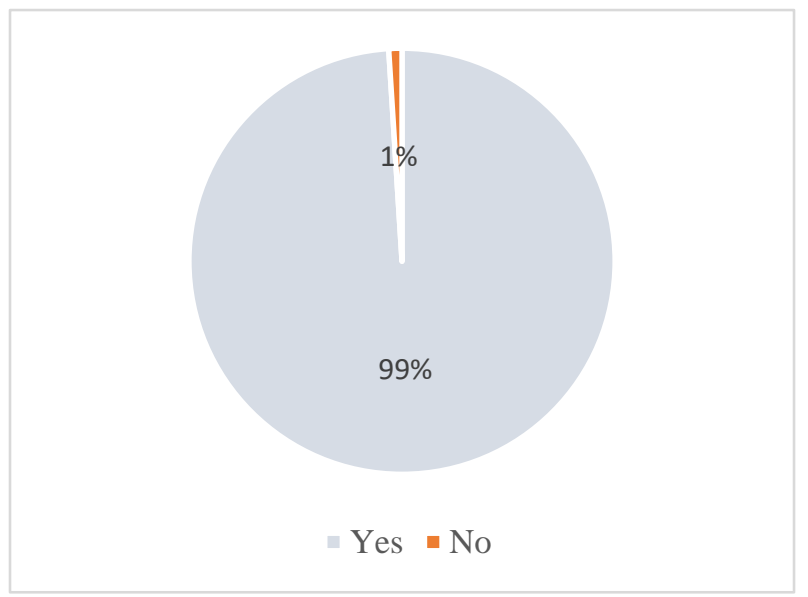

Figure 9. Ability to select modules in the course.

When choosing among General, Business and Field-specific courses (Figure 10), the respondents gave a majority of votes to the option "General" (93\%), whereas Business and field - specific courses were not of much interest to the poll participants ( $5 \%$ and $2 \%$, respectively).

Regarding the location of courses (Figure 11) on the job training got near-unanimous approval among representatives of the academic community. 


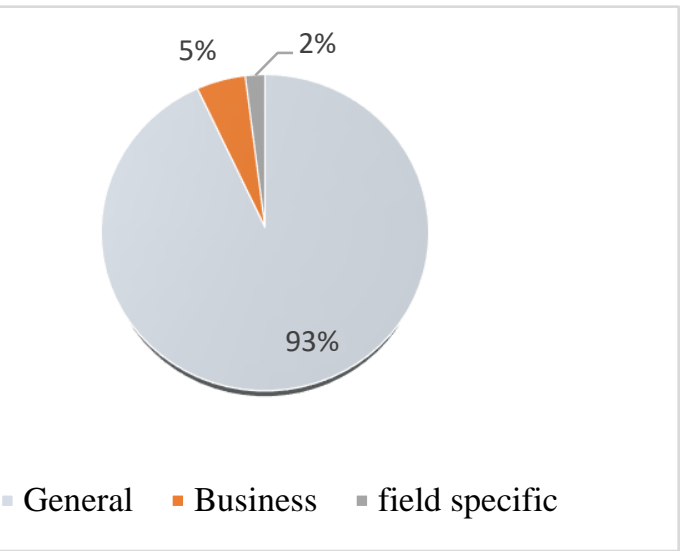

Figure 10. Preferences when choosing a language course.

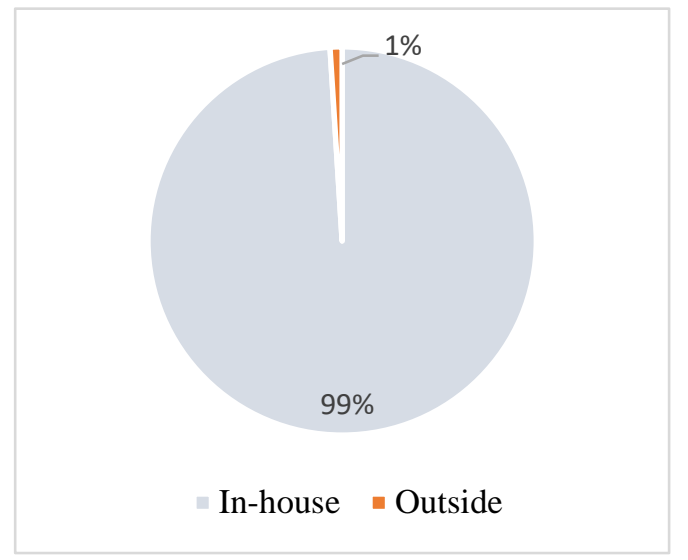

Figure 11. Preferences for course location.

In Plekhanov Russian University of Economics, there is a rating system for structural divisions, which takes into account the number of employees who give lectures in a foreign language. In this regard, the heads of structural divisions are interested in teaching a foreign language to employees. The heads of the structural divisions identified two pools of teachers: teachers who have already taught in a foreign language and teachers who are potentially able to give a lecture in front of a foreign language audience, but they lack general vocabulary. Many teachers note that they know field-specific terminology at a sufficient level, but they lack a general colloquial vocabulary for spontaneous discussion and answers to audience questions.

\section{Conclusions}

The research has indicated that the hypothesis was fully confirmed. Registered findings demonstrate a surge in interest among potential learners towards a suite of short-term and medium-term programs with a duration of up to 3 and 6 months respectively which are highly likely to become the most soughtafter product on the market of further educational services specifically in the field of foreign language learning. To hit planned target indicators of further educational programs' realization it is pivotal to devise unique programs that will allow to take a competitive advantage on the market, taking into consideration that the market of further educational services in the field of foreign language teaching can be defined as saturated. Furthermore, the market itself requires the launch of such educational products which are far beyond the plain catering to the basic educational needs of potential consumers. The research findings and their analysis allowed to identify the main trends in the development of the further educational services market and to delineate a must-be-targeted market segment.

Given the current epidemiological situation, it would be advisable to offer programs in multiformat training: face-to-face, mixed or online. Moreover, the results of the survey clearly showed that the possibility of an optional choice of modules appeared to be alluring for the listeners. A personalized approach to foreign language teaching would ensure the repletion of their individual needs and wants. Moreover, it would be paramount importance to receive snapshot feedback from the learners via surveys or anonymous questionnaires to make amendments into the programs.

The reliability and validity of the data obtained are endorsed by a significant number of interviewees among students and academic staff. Thus, the recomposition of the product line of the Department of Foreign Languages No. 2 will open the floodgates to the brand-new programs to be relaunched in the further educational services market and predictably provide a multiple intake of students' numbers.

\section{Bibliography}

1. Alexandrova G.N., Glukhov G.V. (2021). Role of Additional Education in the Context of Labor Market Volatility. In S.I. Ashmarina, V.V. Mantulenko (Eds.), Digital Economy and the New Labor Market: Jobs, Competences and Innovative HR Technologies. IPM 2020. Lecture Notes in Networks and Systems, 161. Cham, Germany: Springer, doi: 10.1007/978-3-030-60926-9_1

2. Aspin D.N., Chapman J., Hatton M., Sawano Y. (Eds.). (2001). International handbook of lifelong learning. New York: Springer. doi: 10.1007/978-94-010-0916-4

3. Biech E. (2005). Training for Dummies. Hoboken, NJ: Wiley Publishing Inc. 
4. Billett S. (2018). Distinguishing Lifelong Learning from Lifelong Education. Journal of Adult Learning, Knowledge and Innovation, 2(1), 1-7. doi: 10.1556/2059.01.2017.3

5. Cendon E. (2018). Lifelong Learning at Universities: Future Perspectives for Teaching and Learning. Journal of New Approaches in Educational Research 7(2), 81-87. doi: 10.7821/naer.2018.7.320

6. Dyatlov S. (2004). Osnovy teorii chelovecheskogo kapitala [Fundamentals of human capital theory]. SPb: Izd-vo SPbUEF. (in Russian)

7. Formenti L., West L. (2018). Transforming Perspectives in Lifelong Learning and Adult Education: A Dialogue. Springer. doi: 10.1007/978-3-319-96388-4

8. Jarvis P. (2007). Globalisation, lifelong learning, and the learning society: Sociological perspectives. London: Routledge.

9. Kireyev I., Zhabotynska N. (2020). Additional Education as a Way to Increase Qualification in People with Professional Experience. Science Rise: Pedagogical Education, 4(37), 40-44. doi: $10.15587 / 2519-4984.2020 .208526$

10. Knapper Ch.K., Cropley A.J. (2000). Lifelong Learning in Higher Education. London: Routledge.

11. Kovalenko K., Kovalenko N. (2019). The role of additional education in modern Russia. Revista Conrado, 15(69), 49-54. Retrieved from https://conrado.ucf.edu.cu/index.php/conrado/article/view/1038

12. Lemanova P. (2013). Social'naya politika v upravlenii chelovecheskim kapitalom [Social policy in human capital management]. Taganrog: TGPI im. A.P. Chekhova.

13. Lengrand P. (2016). Areas of Learning Basic to Lifelong Education. (Advances in Lifelong Education Book 10). Frankfurt, New York: UNESCO Institute for Education Hamburg and Pergamon Press.

14. Li J. (2014). Needs analysis: an effective way in business English curriculum design. Theory and Practice in Language Studies, 4(9), 1869-1874. doi: 10.4304/tpls.4.9.1869-1874

15. Nunan D. (2013). Learner-Centered English Language Education. The selected works of David Nunan. New York and London: Routledge. doi: 10.4324/9780203096888

16. Oliver P. (Ed.). (2019). Lifelong and Continuing Education: What is a Learning Society? London: Routledge. doi: 10.4324/9780429435386

17. Sharples M. (2000). The design of personal mobile technologies for lifelong learning. Computers and Education, 34(3-4), 177-193. doi: 10.1016/S0360-1315(99)00044-5

18. Sönmez H. (2019). An Examination of Needs Analysis Research in the Language Education Process. International Journal of Education \& Literacy Studies, 7(1), 8-17. doi: 10.7575/aiac.ijels.v.7n.1p.8

19. Tight M. (2003). Key concepts in Adult Education and Training ( $2^{\text {nd }}$ ed). London: Routledge. doi: $10.4324 / 9780203434086$

20. Vaganova O., Sirotyk S., Popkova A., Smirnova Zh., Bulaeva M. (2019). Additional education in higher professional educational institution. Revista Amazonia Investiga, 8(22), 305-310. Retrieved from https://amazoniainvestiga.info/index.php/amazonia/article/view/448/421

21. Wain K. (2016). Philosophy of Lifelong Education. London: Routledge. doi: $10.4324 / 9781315531090$ 